BANCHIERO JÚNIOR, A.M.D. et al. Levantamento soroepidemiológico de leptospirose em rebanhos bovinos leiteiros no Município de Guaíra, SP. PUBVET, Londrina, V. 8, N. 14, Ed. 263, Art. 1746, Julho, 2014.

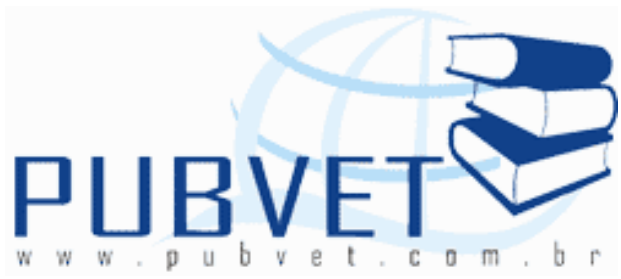

PUBVET, Publicações em Medicina Veterinária e Zootecnia.

\title{
Levantamento soroepidemiológico de leptospirose em rebanhos bovinos leiteiros no Município de Guaíra - SP
}

\section{Antônio Marcos Durães Banchiero Júnior ${ }^{1}$, Laís Miguel Rezende ${ }^{1}$, Mariana} Assunção de Souza², Anna Monteiro Correia Lima-Ribeiro ${ }^{3}$

${ }^{1}$ Médicos Veterinários autônomos

${ }^{2}$ Doutoranda em Medicina Veterinária da FAMEV-UFU

3 Profa. Faculdade de Medicina Veterinária da Universidade Federal de Uberlândia

\section{Resumo}

A Leptospirose é uma zoonose que acomete todos os mamíferos, entre eles os bovinos. A infecção é de caráter agudo a crônico, com grande polimorfismo clínico, sendo provocada por bactérias do gênero Leptospira spp. Sua importância está relacionada as perdas econômicas, pois na maioria das vezes a sintomatologia é de ordem reprodutiva como, abortos, natimortos e infertilidade; ou produtiva como queda na produção de leite e mastites. O objetivo deste estudo foi realizar um levantamento soroepidemiológico nos rebanhos bovinos leiteiros do Município de Guaíra - São Paulo. Foram analisadas 104 amostras de soro sanguíneo de bovinos leiteiros de 5 propriedades, através de pesquisa de anticorpos pelo teste de Soroaglutinação Microscópica (SAM). Juntamente com a análise foi elaborado um questionário epidemiológico a fim de avaliar os fatores de risco para ocorrência da infecção. 
BANCHIERO JÚNIOR, A.M.D. et al. Levantamento soroepidemiológico de leptospirose em rebanhos bovinos leiteiros no Município de Guaíra, SP. PUBVET, Londrina, V. 8, N. 14, Ed. 263, Art. 1746, Julho, 2014.

A prevalência encontrada foi de $46,15 \%$ animais positivos para Leptospirose; os sorovares mais prevalentes foram Hardjo (39,53\%); Grippotyphosa $(24,42 \%)$; Wolffi $(19,77 \%)$ Hebdomadis $(12,79 \%)$; Icterohaemorragiae $(2,33 \%)$ e Pomona $(1,16 \%)$. Observou-se que vacas multíparas apresentaram maior predisposição para ocorrência da doença. A maior prevalência de sorovar Hardjo encontrada nos resultados sugere que a infecção nessas propriedades pode ser pela comercialização de animais, sem conhecimento do manejo sanitário dos mesmos e que a ausência da vacinação é um fator de risco para ocorrência leptospirose.

Palavras-chave: Leptospira spp; Vacas; Soroaglutinação Microscópica;

Prevalência; Questionário Epidemiológico.

\section{Seroepidemiological study of leptospirosis in cattle herds in the city of Guaíra-SP}

\section{Abstract}

Leptospirosis is a zoonosis that affects all mammals, including cattle. The infection acute to the chronic character, with great clinical polymorphism, and is caused by bacteria of the genus Leptospira spp. Its importance is related to causing clinical signs in cattle, which is mostly in the reproductive and abortions, stillbirths and infertility or productive as a drop in milk production and mastitis. The aim of this study was to conduct a seroepidemiological dairy cattle herds in the city of Guaíra - São Paulo. We analyzed 104 samples of blood serum of dairy cattle from 5 properties through antibody testing by Microscopic Agglutination Test (MAT). Besides the test, an epidemiological questionnaire was designed to assess risk factors for the occurrence of infection. The prevalence was $46.15 \%$, the most prevalent serovars were Hardjo(39.53\%); Grippotyphosa (24.42\%); Wolffi (19.77\%) Hebdomadis $(12.79 \%)$; Icterohaemorragiae $(2,33 \%)$ and Pomona $(1.16 \%)$. It was observed that multiparous cows were more prone to disease occurrence. The results suggest that infection in these properties may be due the trade of 
BANCHIERO JÚNIOR, A.M.D. et al. Levantamento soroepidemiológico de leptospirose em rebanhos bovinos leiteiros no Município de Guaíra, SP. PUBVET, Londrina, V. 8, N. 14, Ed. 263, Art. 1746, Julho, 2014.

animals due to the higher prevalence of serovar Hardjo, and that the absence of vaccination is a risk factor for leptospirosis.

Keywords: Leptospira spp; Cows; Microscopic Agglutination Test; Prevalence; Epidemiological questionnaire

\section{INTRODUÇÃO}

A leptospirose é uma zoonose de curso agudo, subagudo e crônico que acomete diversas espécies domésticas, e é provocada por uma bactéria do gênero Leptospira (espiroqueta aeróbica, móvel, exigente aos seus meios nutritivos). Esta possui oito genomas espécies patogênica, distribuídas em 26 sorogrupos e 250 sorovares, porém em bovinos duas leptospiras tem maior importância como patógenos: L. interrogans sorovar Wolffii e L. interrogans sorovar Hardjo (GIRIO; LEMOS, 2007).

A Leptospira é largamente distribuída no ambiente, geralmente estão presentes nos túbulos renais dos mamíferos doentes/portadores e são excretadas na urina freqüentemente por vários meses.

Rios e lagos podem ser vias de infecção, assim como aerossol de urina em estábulos, leite e sêmen de animais infectados. As leptospiras morrem rapidamente quando expostas a dessecação, $\mathrm{pH}$ abaixo de 6 ou acima de 8 , radiação solar e temperaturas inferiores a $7^{\circ} \mathrm{C}$ ou superiores a $36^{\circ} \mathrm{C}$ (RIETCORREA et al., 2001). Por causa da importância da água como meio de disseminação da infeç̧ão, casos novos são mais prováveis de ocorrer nas estações úmidas e em áreas baixadas, especialmente quando a contaminação e a suscetibilidade são altas. A Leptospirose é transmitida pela urina de animais infectados, chamados de portadores. Esses portadores são considerados assintomáticos (animais sadios que se curam e continuam infectados), o que proporciona a manutenção da doença nas áreas de alta prevalência. Entre os portadores, os roedores são considerados os hospedeiros mais importantes, pois contaminam os ambientes, pela urina, introduzindo a 
BANCHIERO JÚNIOR, A.M.D. et al. Levantamento soroepidemiológico de leptospirose em rebanhos bovinos leiteiros no Município de Guaíra, SP. PUBVET, Londrina, V. 8, N. 14, Ed. 263, Art. 1746, Julho, 2014.

doença nos rebanhos, assim o bovino infectado irá transmitir a doença para o restante do plantel. Touros infectados também podem veicular as leptospiras pelo sêmen, transmitindo o agente tanto na cobertura natural como na inseminação artificial (SILVA, 2006).

O diagnóstico da doença se baseia através dos achados clínicos, em que os quadros clínicos comuns são abortos, problemas de fertilidade e queda na produção de leite, como essa sintomatologia é comum entre doenças reprodutivas e necessário realizar um diagnóstico diferencial. Como se trata de uma doença de rebanho e tem como características infecções prolongadas em bovinos, o diagnóstico é feito através da detecção de anticorpos no sangue circulante, com recomendação de uma amostragem de 10 a 20\% dos animais do rebanho incluindo animais doentes e sadios (SILVA, 2006). A pesquisa de anticorpos é a principal prova de diagnóstico na leptospirose, que inclui testes sorogrupo-específicos, constituindo como as principais e mais importantes dentre essas provas, compreendendo a prova de soroaglutinação microscópica (SAM) e suas variações em relação ao tipo de antígeno empregado, vivo ou inativado (GIRIO; LEMOS, 2007).

O controle da leptospirose tem por objetivo a erradicação ou a profilaxia da enfermidade em questão. A erradicação só seria conseguida se as medidas adotadas fossem suficientes para romper os elos da cadeia epidemiológica da doença. O controle se baseia através da higienização, no tratamento dos doentes e portadores; e na vacinação dos animais susceptíveis (FILHO et al., 2005).

A vacinação é uma importante ação preventiva contra a infecção dos animais por leptospiras; em condições de campo, o uso de vacinas contra leptospirose reduz a ocorrência da infecção e os problemas reprodutivos causados pelo sorovar Hardjo (BOLIN et al., 1989). Porém nem sempre é possível evitar novas infecções com a doença através da vacinação, pois as leptospiras são antígenos pobres, induzem respostas imunológicas baixas e por um curto período de tempo e é específico para cada sorovar, o que faz das vacinas comerciais uma medida profilática muitas vezes ineficiente (BOLIN et 
BANCHIERO JÚNIOR, A.M.D. et al. Levantamento soroepidemiológico de leptospirose em rebanhos bovinos leiteiros no Município de Guaíra, SP. PUBVET, Londrina, V. 8, N. 14, Ed. 263, Art. 1746, Julho, 2014.

al., 1991). A dificuldade que o produtor rural encontra quando se depara com a doença, está nos seus prejuízos econômicos: queda na produção de leite (conhecida como Síndrome da Queda do Leite), diminuição no número de nascimentos de bezerros (abortos no terço final da gestação), aumento da mortalidade de bezerros e mastite com sangue (RIBEIRO et al., 2010).

Os prejuízos econômicos causados pela Leptospirose são relatados por De Vries (2006) o qual concluiu que o custo de uma nova gravidez para bovinos Holandesas de leite, em média é de US \$278 e o custo médio de um aborto foi de US $\$ 555$, valores simulados em um rebanho pertencente ao Estados Unidos, sendo os preços estimados em dólares.

Tendo em vista que a leptospirose é uma zoonose de ampla distribuição geográfica, que acarreta prejuízos não só em saúde pública, em face da alta incidência de casos humanos, como também econômicos devido alterações na esfera reprodutiva em bovinos infectados, podendo determinar abortos, subfertilidade e mastite com queda na produção leiteira.O objetivo deste trabalho foi realizar o levantamento soroepidemiológico de Leptospirose em cinco propriedades rurais do Município de Guaíra, São Paulo, avaliando a prevalência da doença,levando em consideração a sua categoria animal (ou seja animais primíparas ou multíparas), vacinação para leptospirose, incidência de abortos e fatores de risco como presença de roedores e ausência de esgoto.

\section{MATERIAIS E MÉTODOS}

O trabalho foi realizado na zona rural do Município de Guaíra São Paulo,

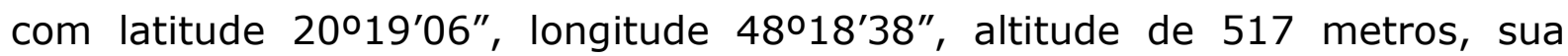
economia básica destaca-se pela agriculta, pecuária e agroindústria. 0 município possui um clima subtropical, com duas estações definidas: verão chuvoso e inverno seco; com precipitação pluviométrica de média anual de $1.550 \mathrm{~mm}$ e temperatura em média de $25^{\circ} \mathrm{C}$. 
BANCHIERO JÚNIOR, A.M.D. et al. Levantamento soroepidemiológico de leptospirose em rebanhos bovinos leiteiros no Município de Guaíra, SP. PUBVET, Londrina, V. 8, N. 14, Ed. 263, Art. 1746, Julho, 2014.

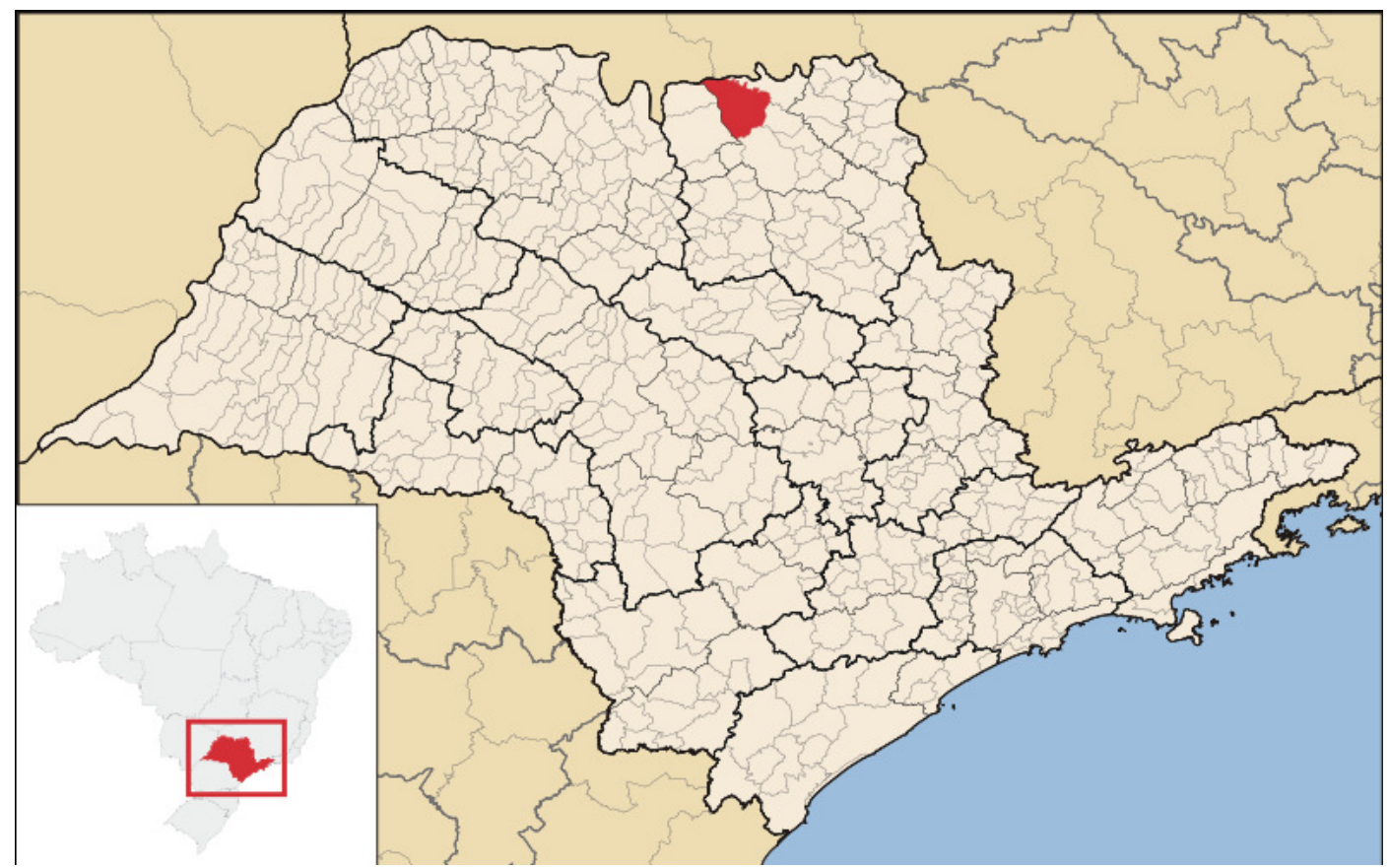

Figura 1. Localização do município de Guaíra, SP.

Fonte: FUNDAÇÃO WIKIPÉDIA (2011).

Foram selecionadas cinco propriedades rurais do Município de Guaíra, SP para esse estudo, sendo todas produtoras de leite, independentemente de está ser a principal atividade produtiva exercida na propriedade. Além disso, admitiu-se como critério de seleção, estas propriedades, apresentarem alterações reprodutivas, como repetição de cio e abortos, conforme foi relatado pelos proprietários. O número de amostras variou pela disponibilidade e quantidade de animais de cada propriedade, todas foram submetidas ao teste de Soroaglutinação microscópica (SAM), não houve realização de exames clínicos nos animais analisados. (Tabela 1 ).

Foram utilizadas fêmeas bovinas voltadas para a produção de leite, totalizando 104 animais distribuídos aleatoriamente. Estes animais tinham como sistema de produção o modo semi-intensivo, sendo que nas águas, sua alimentação era basicamente á pasto, e na seca havia suplementação dos animais no cocho com silagem e concentrado, em todas as propriedades. 
BANCHIERO JÚNIOR, A.M.D. et al. Levantamento soroepidemiológico de leptospirose em rebanhos bovinos leiteiros no Município de Guaíra, SP. PUBVET, Londrina, V. 8, N. 14, Ed. 263, Art. 1746, Julho, 2014.

Tabela 1. Número de amostras colhidas dos bovinos leiteiros nas 5 propriedades

\begin{tabular}{cc}
\hline PROPRIEDADE & No DE ANIMAIS ANALISADOS \\
\hline 1 & 15 \\
2 & 28 \\
3 & 24 \\
4 & 9 \\
5 & 28 \\
\hline TOTAL & $\mathbf{1 0 4}$ \\
\hline
\end{tabular}

As amostras foram colhidas durante o período de Julho a Agosto de 2011. Sendo coletado amostras de $5 \mathrm{~mL}$ de sangue por meio de punção da veia coccígea em tubos vaccutainer sem anticoagulante.

O material foi transportado refrigerado $\left(2\right.$ a $\left.8^{\circ} \mathrm{C}\right)$ ao Laboratório de Doenças Infectocontagiosas da Faculdade de Medicina Veterinária (FAMEV) da Universidade Federal de Uberlândia (UFU) e centrifugado a 2.500 rpm, durante 5 minutos. Em seguida, as amostras de soro foram acondicionadas em tubos plástico tipo eppendorf e congeladas a $-20^{\circ} \mathrm{C}$ até a realização dos exames.

O exame de Soroaglutinação Microscópica (SAM) foi realizado no Laboratório de Doenças Infectocontagiosas da Faculdade de Medicina Veterinária (FAMEV) da Universidade Federal de Uberlândia (UFU).

Foi utilizada a técnica de SAM conforme Brasil (1995) com uma coleção de 12 antígenos vivos que inclui os sorovares: Autumnalis, Australis, Bataviae, Bratislava, Canicola, Grippothyphosa, Hardjo, Hebdomadis, Pomona, Icterohaemorrhagiae, Tarassovi e Wolffi; padronizando como positivos os títulos maiores ou iguais a $50 \%$ de aglutinação de antígenos por campo a uma diluição de 1:100 do soro sanguíneo.

Os antígenos de leptospiras foram mantidos no laboratório em estufa a $28{ }^{\circ} \mathrm{C}$ e repicadas semanalmente, em meio líquido Stuart, enriquecido com $10 \%$ de soro estéril de coelho. Foram utilizados apenas cultivos puros, móveis, isentos de contaminação, livres de auto-aglutinação, com cinco a sete dias de crescimentos. As amostras de soros foram diluídas em solução salina 
BANCHIERO JÚNIOR, A.M.D. et al. Levantamento soroepidemiológico de leptospirose em rebanhos bovinos leiteiros no Município de Guaíra, SP. PUBVET, Londrina, V. 8, N. 14, Ed. 263, Art. 1746, Julho, 2014.

tamponada, inicialmente na diluição 1:50; assim foram colocadas alíquotas de $50 \mu \mathrm{l} \mathrm{em} \mathrm{microplacas} \mathrm{e} \mathrm{adicionadas} \mathrm{igual} \mathrm{quantidade} \mathrm{de} \mathrm{antígeno,} \mathrm{resultando}$ na diluição de 1:100 para triagem. A leitura das reações foi realizada em microscópio de campo escuro, após a incubação da mistura soro-antígeno por uma a duas horas em temperatura de $28^{\circ} \mathrm{C}$. Os reagentes são considerados aqueles soro com no mínimo $50 \%$ de aglutinação, ou seja, metade das leptospiras aglutinadas no microscópio em aumento de 100 vezes. As amostras reagentes, na triagem, foram novamente examinadas em diluições crescentes de 1:200 até $1: 32000$, considerando-se como título do soro a recíproca da sua maior diluição a apresentar $50 \%$ de aglutinação.

Foi realizado um questionário epidemiológico (Anexo - A), para o recolhimento de informações para o estudo epidemiológico da leptospirose bovina na região. Para cada propriedade rural, os proprietários responderam perguntas referentes aos pontos determinantes da doença como: idade, vacinação para leptospirose, incidência de abortos e fatores de risco como presença de roedores e ausência de esgoto. A análise estatística baseou-se numa análise descritiva dos dados com cálculo do percentual simples, segundo Morettin; Bussab (2003).

\section{RESULTADOS}

Das 104 amostras de soro examinadas pelo teste de soroaglutinação microscópica, 48 apresentaram reações positivas, com títulos iguais ou superiores a $1: 100$, resultando em uma taxa de prevalência de $46,15 \%$.

A tabela 2 ilustra a distribuição dos títulos observados e a prevalência dos sorovares. Os títulos encontrados foram: 1:100 (58,14\%); 1:200 $(30,23 \%) ; 1: 400(9,3 \%)$ e $1: 800(2,33 \%)$.

Das 48 amostras reagentes, 22 (45,83\%) apresentaram anticorpos aglutinantes para mais de um sorovar, conforme enumerado os dados da Tabela 3. 
BANCHIERO JÚNIOR, A.M.D. et al. Levantamento soroepidemiológico de leptospirose em rebanhos bovinos leiteiros no Município de Guaíra, SP. PUBVET, Londrina, V. 8, N. 14, Ed. 263, Art. 1746, Julho, 2014.

Tabela 2. Números de reagentes ao teste de soroaglutinação microscópica para o diagnóstico de leptospirose bovina, de acordo com as sorovariedades e seus respectivos títulos, no município de Guaíra, SP, 2011.

\begin{tabular}{lllllll}
\hline & \multicolumn{7}{c}{ Título } \\
\cline { 2 - 7 } & $\mathbf{1 0 0}$ & $\mathbf{2 0 0}$ & $\mathbf{4 0 0}$ & $\mathbf{8 0 0}$ & $\mathbf{( \% ) *}$ & Total \\
\hline Sorovar & 8 & 9 & 3 & 1 & 24,42 & 21 \\
Grippotyphosa & 13 & 15 & 5 & 1 & 39,53 & 34 \\
Hardjo & 10 & 1 & - & - & 12,79 & 11 \\
Hebdomadis & 2 & - & - & - & 2,33 & 2 \\
Icterohaemorragiae & 1 & - & - & - & 1,16 & 1 \\
Pomona & 16 & 1 & - & - & 19,77 & 17 \\
Wolffi & 16 & & & & & \\
\hline
\end{tabular}

*Frequência dos animais reagentes

Tabela 3. Números de casos de coaglutinações no teste de soroaglutinação microscópica, no município de Guaíra, SP, 2011.

\begin{tabular}{lc}
\hline Tipos de coaglutinação & No de casos \\
\hline Grippotyphosa + Wolffi & 5 \\
Grippotyphosa + Hardjo & 2 \\
Hebdomadis + Wolffi & 2 \\
Hardjo + Icterohaemorragiae & 1 \\
Hardjo + Hebdomadis & 1 \\
Grippotyphosa + Hebdomadis + Wolffi & 2 \\
Grippotyphosa + Hardjo + Wolffi & 3 \\
Grippotyphosa + Hardjo + Hebdomadis & 1 \\
Grippotyphosa + Hebdomadis + Wolffi & 5 \\
\hline Total & $\mathbf{2 2}$ \\
\hline
\end{tabular}

$\mathrm{Na}$ tabela 4 está apresentada a porcentagem de bovinos reagentes, segundo a localidade do município estudada. Das 5 propriedades estudadas, todas apresentaram animais reagentes no teste do SAM, sendo as 
BANCHIERO JÚNIOR, A.M.D. et al. Levantamento soroepidemiológico de leptospirose em rebanhos bovinos leiteiros no Município de Guaíra, SP. PUBVET, Londrina, V. 8, N. 14, Ed. 263, Art. 1746, Julho, 2014.

propriedades de $\mathrm{n}^{0} 1$ e $\mathrm{n}^{\circ} 3$, as que apresentaram menor e maior porcentagem de animais positivos respectivamente.

Tabela 4. Distribuição espacial dos resultados obtidos pelo teste de soroaglutinação microscópica, no município de Guaíra, SP, 2011.

\begin{tabular}{|c|c|c|c|}
\hline \multirow[t]{2}{*}{ Propriedade } & \multirow{2}{*}{$\begin{array}{l}\text { No de animais } \\
\text { examinados }\end{array}$} & \multicolumn{2}{|c|}{ No de animais reagentes } \\
\hline & & Positivos & $(\%)$ \\
\hline 1 & 15 & 4 & 26,66 \\
\hline 2 & 28 & 14 & 50 \\
\hline 3 & 24 & 16 & 66,66 \\
\hline 4 & 9 & 4 & 44,44 \\
\hline 5 & 28 & 10 & 35,71 \\
\hline Total & 104 & 48 & 46,15 \\
\hline
\end{tabular}

A tabela 5 representa a distribuição dos sorovares e os títulos observados em cada propriedade em que se foi analisada o rebanho em questão. Analisou-se também a frequência de sorovares em relação ao total de animais analisados em todas propriedades.

Através das informações obtidas no questionário aplicado aos produtores que está em anexo, foi possível traçar um perfil epidemiológico do rebanho, baseado no manejo dessas propriedades.

Observando os animais em relação à categoria animal, ou seja, vacas primíparas ou multíparas, verificou-se que as taxas de prevalência das fêmeas multíparas foi maior em relação as fêmeas primíparas, como se pode observar na tabela 6. 
BANCHIERO JÚNIOR, A.M.D. et al. Levantamento soroepidemiológico de leptospirose em rebanhos bovinos leiteiros no Município de Guaíra, SP. PUBVET, Londrina, V. 8, N. 14, Ed. 263, Art. 1746, Julho, 2014.

Tabela 5. Números de amostras reagentes ao teste de Soroaglutinação microscópica, em cada propriedade, de acordo com as sorovariedades e seus respectivos títulos, no município de Guaíra, SP, 2011.

\begin{tabular}{|c|c|c|c|c|c|c|c|}
\hline & \multirow[b]{2}{*}{ Sorovares } & \multicolumn{6}{|c|}{ Títulos } \\
\hline & & 100 & 200 & 400 & 800 & $(\%)$ & Total \\
\hline & Grippotyphosa & 0 & 1 & 0 & 0 & 1,16 & $\overline{1}$ \\
\hline & Hardjo & 1 & 0 & 0 & 0 & 1,16 & 1 \\
\hline \multirow[t]{6}{*}{ Propriedade 1} & Hebdomadis & 2 & 0 & 0 & 0 & 2,33 & 2 \\
\hline & Icterohaemorragiae & 0 & 0 & 0 & 0 & 0 & 0 \\
\hline & Pomona & 0 & 0 & 0 & 0 & 0 & 0 \\
\hline & Wolffi & 3 & 0 & 0 & 0 & 3,49 & 3 \\
\hline & Grippotyphosa & 5 & 3 & 3 & 0 & 12,79 & 11 \\
\hline & Hardjo & 5 & 1 & 0 & 0 & 6,98 & 6 \\
\hline \multirow[t]{7}{*}{ Propriedade 2} & Hebdomadis & 4 & 0 & 0 & 0 & 4,65 & 4 \\
\hline & Icterohaemorragiae & 1 & 0 & 0 & 0 & 1,16 & 1 \\
\hline & Pomona & 0 & 0 & 0 & 0 & 0 & 0 \\
\hline & Wolffi & 6 & 1 & 0 & 0 & 8,14 & 7 \\
\hline & Grippotyphosa & 1 & 1 & 0 & 0 & 2,33 & 2 \\
\hline & Hardjo & 2 & 10 & 2 & 1 & 17,44 & 15 \\
\hline & Hebdomadis & 1 & 0 & 0 & 0 & 1,16 & 1 \\
\hline \multirow[t]{5}{*}{ Propriedade 3} & Icterohaemorragiae & 0 & 0 & 0 & 0 & 0 & 0 \\
\hline & Pomona & 1 & 0 & 0 & 0 & 1,16 & 1 \\
\hline & Wolffi & 1 & 0 & 0 & 0 & 1,16 & 1 \\
\hline & & 0 & 2 & 0 & 0 & 4,65 & 4 \\
\hline & Grippotyphosa & 2 & 4 & 3 & 0 & 11,63 & 10 \\
\hline \multirow[t]{7}{*}{ Propriedade 4} & Hardjo & 2 & 1 & 0 & 0 & 2,33 & 2 \\
\hline & Hebdomadis & 0 & 0 & 0 & 0 & 1,16 & 1 \\
\hline & Icterohaemorragiae & 0 & 0 & 0 & 0 & 0 & 0 \\
\hline & Pomona & 3 & 0 & 0 & 0 & 3,49 & 3 \\
\hline & Wolffi & & & & & & \\
\hline & Grippotyphosa & 2 & 2 & 0 & 0 & 4,65 & 4 \\
\hline & Hardjo & 3 & 4 & 3 & 0 & 11,63 & 10 \\
\hline \multirow[t]{4}{*}{ Propriedade 5} & Hebdomadis & 1 & 1 & 0 & 0 & 2,33 & 2 \\
\hline & Icterohaemorragiae & 1 & 0 & 0 & 0 & 1,16 & 1 \\
\hline & Pomona & 0 & 0 & 0 & 0 & 0 & 0 \\
\hline & Wolffi & 3 & 0 & 0 & 0 & 3,49 & 3 \\
\hline
\end{tabular}


BANCHIERO JÚNIOR, A.M.D. et al. Levantamento soroepidemiológico de leptospirose em rebanhos bovinos leiteiros no Município de Guaíra, SP. PUBVET, Londrina, V. 8, N. 14, Ed. 263, Art. 1746, Julho, 2014.

Tabela 6. Resultado de soroaglutinação microscópica, em relação a Categoria Animal,no município de Guaíra, SP, 2011.

\begin{tabular}{|c|c|c|c|c|c|}
\hline \multirow{3}{*}{$\begin{array}{l}\text { Categoria } \\
\text { Animal }\end{array}$} & \multirow{2}{*}{\multicolumn{2}{|c|}{$\begin{array}{l}\text { Animais } \\
\text { Reagentes }\end{array}$}} & \multirow{2}{*}{\multicolumn{2}{|c|}{$\begin{array}{l}\text { Animais Não } \\
\text { Reagentes }\end{array}$}} & \multirow[t]{3}{*}{ Total } \\
\hline & & & & & \\
\hline & $\mathbf{N}^{\circ}$ & $(\%)$ & No & $(\%)$ & \\
\hline Primípara & 14 & 36,84 & 24 & 63,16 & 38 \\
\hline Multípara & 34 & 51,52 & 32 & 48,48 & 66 \\
\hline Total & 48 & 46,15 & 56 & 53,85 & 104 \\
\hline
\end{tabular}

Nas cinco propriedades estudadas no município de Guaíra, SP, todas relataram problemas com abortos. Através do SAM verificamos que a taxa de prevalência dos animais positivos para leptospirose que não apresentaram quadro de aborto, foi maior do que a taxa encontrada nos animais também positivos, porém que abortaram. Já nos animais comprovadamente negativos ocorreu o inverso os animais que apresentavam esse distúrbio reprodutivo obtiveram taxa de prevalência maior em relação aos animais que não abortaram.

Tabela 7. Presença de abortos de acordo com o resultado do teste de soroaglutinação microscópica, no município de Guaíra, SP, 2011.

\begin{tabular}{llcccc}
\hline Abortos & \multicolumn{2}{l}{$\begin{array}{l}\text { Animais } \\
\text { Reagentes }\end{array}$} & \multicolumn{2}{l}{$\begin{array}{l}\text { Animais Não } \\
\text { Reagentes }\end{array}$} \\
\cline { 2 - 6 } & $\mathbf{N}^{\mathbf{2}}$ & $\mathbf{( \% )}$ & $\mathbf{N}^{\mathbf{0}}$ & $\mathbf{( \% )}$ \\
\hline Presença & 9 & 45 & 11 & 55 & 20 \\
Ausência & 39 & 46,43 & 45 & 53,57 & 84 \\
\hline Total & 48 & 46,15 & 56 & 53,85 & 104 \\
\hline
\end{tabular}


BANCHIERO JÚNIOR, A.M.D. et al. Levantamento soroepidemiológico de leptospirose em rebanhos bovinos leiteiros no Município de Guaíra, SP. PUBVET, Londrina, V. 8, N. 14, Ed. 263, Art. 1746, Julho, 2014.

Em relação a imunidade dos animais, foi relatado pelos proprietários que duas das cinco propriedades vacinavam o rebanho todo; deste modo observouse que a taxa de prevalência dos animais vacinados porém positivos foi menor do que a dos animas positivos não vacinados, como se pode observar na tabela 8.

Tabela 8. Resultado do teste de Soroaglutinação Microscópica, em relação a vacinação contra Leptospirose, no município de Guaíra, SP, 2011.

\begin{tabular}{llcccc}
\hline Vacinação & \multicolumn{2}{l}{$\begin{array}{l}\text { Animais } \\
\text { Reagentes }\end{array}$} & \multicolumn{2}{l}{$\begin{array}{l}\text { Rnimais Não } \\
\text { Reagentes }\end{array}$} \\
\cline { 2 - 6 } & $\mathbf{N}^{\mathbf{N}}$ & $\mathbf{( \% )}$ & $\mathbf{N}^{\mathbf{0}}$ & $\mathbf{( \% )}$ \\
\hline Vacinados & 8 & 33,33 & 16 & 66,67 & 24 \\
Não Vacinados & 40 & 50 & 40 & 50 & 80 \\
\hline Total & 48 & 46,15 & 56 & 53,85 & 104 \\
\hline
\end{tabular}

Através do questionário foi relatado que nas cinco propriedades os animais possuíam contato com roedores; e também todas possuíam esgoto e água tratada; portanto a taxa de prevalência de animais reagentes a leptospirose tanto para a presença de roedores como para a presença de esgoto são de $100 \%$; portanto tais dados não podem ser analisados como fatores de risco, neste trabalho.

\section{DISCUSSÃo}

Os resultados obtidos neste estudo demonstram os elementos relativos ao perfil sorológico e epidemiológico da leptospirose bovina no município de Guaíra, estado de São Paulo; a prevalência encontrada da doença foi de $46,15 \%$ (48/104 animais), o que se assemelha ao trabalho de Castro et al. 
BANCHIERO JÚNIOR, A.M.D. et al. Levantamento soroepidemiológico de leptospirose em rebanhos bovinos leiteiros no Município de Guaíra, SP. PUBVET, Londrina, V. 8, N. 14, Ed. 263, Art. 1746, Julho, 2014.

(2008) que analisou a soroprevalência da leptospirose bovina no Estado de São Paulo, em 7 regiões, e obteve uma taxa de prevalência de animais positivos de $49,4 \%$, aproximando-se então dos dados do presente trabalho.

No mesmo município, Guaíra - SP foram realizados os mesmos testes, de soroaglutinação microscópica, por Rende; Ávila (2003); porém com uma amostragem maior, de 309 bovinos de leite; sendo que a taxa de prevalência de animais reagentes ao teste foi de $(59,2 \%)$; isto pode ser explicado pela diminuição da atividade leiteira na cidade, consequentemente, diminuição da venda de animais entre propriedades, o que poderia desta forma carrear a Leptospira em diferentes locais no município. Outra explicação para essa diferença de porcentagem deve-se ao fato de que há uma maior organização entre os produtores, consequentemente uma conscientização em relação ao manejo sanitário de seus rebanhos. A prevalência da doença depende da região e dos índices pluviométricos de cada período como demonstrado por Mineiro et al. (2007) no Norte do Estado do Piauí, em que se analisou a quantidade de animais positivos e verificou-se uma porcentagem de soropositivos de 42,64\% na estação de seca; aproximadamente ao encontrado neste trabalho, já que todos os dados foram coletados na mesma estação, mostrando a importância da sazonalidade da doença para o rebanho. Os resultados da soroaglutinação microscópica para Leptospira spp. nas cinco propriedades do município de Guaíra, indicaram uma variação na porcentagem de positividade de $26,66 \%$ a $66,66 \%$; variação esta, que também pode ser vista nos trabalhos de Tenório et al. (2005) o qual teve como resultado em Pernambuco uma taxa de prevalência de animais positivos de $57,7 \%$ e Tomich et al. (2009) na Região de Corumbá - MS com taxa de prevalência de positivos de $36,1 \%$. Porém há relatos de prevalência mais baixa do que há encontrada neste estudo; como descrito em por Langoni et al. (2000) com taxa de prevalência de positivos de $24,06 \%$ no mesmo estado do trabalho em questão, São Paulo; por Mendes et al (2011) com um percentual de $15,87 \%$ de positivos em Uberaba - MG; por Viana et al. (2010) na Bacia leiteira de 
BANCHIERO JÚNIOR, A.M.D. et al. Levantamento soroepidemiológico de leptospirose em rebanhos bovinos leiteiros no Município de Guaíra, SP. PUBVET, Londrina, V. 8, N. 14, Ed. 263, Art. 1746, Julho, 2014.

Caparaó, Estado do Espírito Santo, através do mesmo teste obteve um resultado de $12,42 \%$ de positivos.

Existem relatos de prevalência mais alta de animais positivos; como descrito por Moreira et al. (2010) em Goiandira, Estado de Goiás, com taxa de prevalência ao SAM de 87,2\%; por Figueiredo et al. (2009) no Estado de Mato Grosso de Sul com 85,2\% de positivos à Leptospira spp; por Souza et al. (2009) com reação positiva para $68,75 \%$ no município de Uberlândia, estado de Minas Gerais.

A predominância dos sorovares neste estudo foi de Hardjo (39,53\%); Grippotyphosa (24,42\%); Wolffi (19,77\%); Hebdomadis (12,79\%); Icterohaemorragiae (2,33\%); Pomona $(1,16 \%)$; se aproximando ao encontrado em Rende; Ávila (2003) no qual o sorovar mais encontrado também foi Hardjo (21,9\%), porém houve uma diferença em relação a um sorovar encontrado, pois neste trabalho realizado em 2001 no município de Guaíra - SP foi encontrado o sorovar Autumnallis com um percentual de 22,4 $\%$, o qual não foi encontrado neste trabalho; indicando portanto uma possível predominância de alguns sorovares durante certos períodos do ano.

O sorovar Hardjo foi o mais encontrado dentre todas as propriedades $(39,53 \%)$, indo de encontro com alguns trabalhos que obtiveram o mesmo sorovar como o de maior prevalência; deste modo há uma concordância com o estudo realizado no Norte do Estado de Piauí por Mineiro et al. (2007) em que o percentual de animais positivos para este sorovar foi 39,50\%; resultado próximo ao deste estudo.

Há outros relatos do sorovar Hardjo sendo o predominante entre os rebanhos, porém com percentuais diferentes como de Castro et al. (2008) com 46\%; Viana et al. (2010) com 12,42\%; Figueiredo et al. (2009) com 65,6\% e Favero et al. (2011) com 48,18\% de prevalência. Contudo outros trabalhos como os de; Langoni et al. (2000), Moreira et al. (2010), Marques et al. (2010) apresentam o sorovar Wolffi como o mais encontrado,já o trabalho de Tenório et al. (2005) possui predominância do sorovar Patoc. A predominância do sorovar Hardjo nos trabalhos leva a crer que a sua disseminação não depende 
BANCHIERO JÚNIOR, A.M.D. et al. Levantamento soroepidemiológico de leptospirose em rebanhos bovinos leiteiros no Município de Guaíra, SP. PUBVET, Londrina, V. 8, N. 14, Ed. 263, Art. 1746, Julho, 2014.

das condições regionais, pois este está presente em estudos de vários locais do Brasil, mais sim pelo tipo de exploração econômica e das práticas reprodutivas (OLIVEIRA, 2008).

Essa elevada predominância do sorovar Hardjo pode se explicada segundo Rende; Ávila (2003); pelo frequente comércio de animais entre as propriedades rurais, sem o conhecimento do histórico de vacinação dos animais, tal fato foi verificado através de relatos dos proprietários; pois este sorovar é disseminado através da transmissão direta entre os bovinos em propriedades abertas.

O sorovar Gryppotyphosa (24,42\%) é o segundo sorovar, mas frequente nesse trabalho, porém seu resultado em percentual é muito superior aos trabalhos anteriormente relatados como de Langoni et al. (2000) 5,56\%; Castro et al. (2008) 3,9\%; Moreira et al. (2010) 5,07\%; Marques et al. (2010) $10,55 \%$.

O terceiro sorovar mais encontrado neste estudo é o sorovar Wolffi com um percentual de $19,77 \%$ que se assemelha aos percentuais encontrados por Castro et al. (2008) 21\%; e por Moreira et al. (2010) 21,74\%. Há estudos em que a taxa de prevalência encontrada deste sorovar é maior, é o caso de Mineiro et al. (2007) 26,7\%; de Langoni et al. (2000) estudo feito em São Paulo com prevalência de 70,59\%; e de Rende; Ávila (2003) em Ipuã $(68,1 \%)$ e Miguelópolis (50\%), municípios localizados a poucos quilômetros do município de Guaíra - SP. De mesmo modo há relatos do sorovar Wolffi com taxa de prevalência menor do que encontrada no município de Guaíra - SP: Viana et al. (2010) 2,42\%; Figueiredo et al. (2009) 12,3\%; Marques et al. (2010) 14,53\% e Favero et al. (2011) 13,3\%.

O sorovar Hebdomadis, encontrado nas amostras, teve um percentual de $12,79 \%$ se assemelhando a taxa de prevalência encontrada por Mineiro et al. (2007) no Norte do Estado do Piauí, que foi de 12,2\%; mostrando a importância desse sorovar no período de coleta das amostras, já que ambos trabalhos foram coletados em estações iguais, porém em anos diferentes. 
BANCHIERO JÚNIOR, A.M.D. et al. Levantamento soroepidemiológico de leptospirose em rebanhos bovinos leiteiros no Município de Guaíra, SP. PUBVET, Londrina, V. 8, N. 14, Ed. 263, Art. 1746, Julho, 2014.

Para o sorovar Icterohaemorrhagiae foi encontrada uma taxa de prevalência de 2,33\%, sendo inferior ao encontrado por Langoni et al. (2000) de 3,97\% no Estado de São Paulo; por Moreita et al. (2010) de 7,25\% no Estado de Goiás; e por Rende Ávila (2001) de 8,1\%.

O sorovar Pomona teve taxa de prevalência de 1,16\%, muito inferior ao que foi relatado por Lagoni et al. (2000) em diferentes regiões no Estado de São Paulo, com uma prevalência de 10,81\% para esse sorovar.

Correlacionando a reação de positividade do teste com a presença de aborto nos rebanhos indicou que os animais que apresentaram esse distúrbio reprodutivo e eram reagentes ao teste de soroaglutinação, possuem uma taxa de prevalência de 45\%; indicando-nos, portanto que a causa desses abortos poderiam ter outra etiologia diferente da Leptospira spp., como problemas de cunho nutricional, ou outras doenças abortíferas;o trabalho de Castro et al. (2008) também não encontrou nenhuma diferença estatística entre animais com e sem presença de aborto nas propriedades de diferentes regiões do Estado de São Paulo.

Com relação as vacas multíparas apresentarem uma taxa de prevalência maior que as primíparas, 51,52 e $36,84 \%$ respectivamente, indica que as multíparas possuem um fator de risco maior que as vacas primíparas; porém não há relatos na literatura especificando cada categoria animal com uma possível suscetibilidade à infecção.

\section{CONCLUSÃO}

Nos rebanhos de bovinos de leite estudados no município de Guaíra, SP, no ano de 2011, a taxa de prevalência da leptospirose foi de $46,15 \%$; sendo que todas as propriedades analisadas possuíam animais reagentes no teste de soroaglutinação microscópica, com prevalência variando entre 26,66 e $66,66 \%$. 
BANCHIERO JÚNIOR, A.M.D. et al. Levantamento soroepidemiológico de leptospirose em rebanhos bovinos leiteiros no Município de Guaíra, SP. PUBVET, Londrina, V. 8, N. 14, Ed. 263, Art. 1746, Julho, 2014.

A taxa de prevalência de sorovares entre as propriedades foram: Hardjo (39,53\%); Grippothyphosa (24,42\%); Wolffi $(19,77 \%)$; Hebdomadis $(12,79 \%)$; Icterohaemorrhagiae $(2,33 \%)$; Pomona $(1,16 \%)$.

Verificou-se que as vacas multíparas possuem um fator de risco maior em relação às primíparas, já que as taxas de prevalência entre as duas categorias foram $51,52 \%$ e $36,84 \%$ respectivamente.

Pode haver outro agente que esteja relacionado aos casos de abortos entre os animais, pois $55 \%$ dos animais que abortaram não foram reagentes para o teste de soroaglutinação microscópica.

A não vacinação dos animais é outro fator de risco para a prevalência da doença; pois através dos dados $50 \%$ dos animais não vacinados foram reagentes no diagnóstico; em contrapartida 33,33\% dos animais vacinados foram reagentes ao teste de soroaglutinação microscópica à Leptospira spp.

\section{REFERÊNCIAS}

ANZAI, E. K. Utilização da PCR para o Diagnóstico da Leptospirose em Cães naturalmente infectados por Leptospira spp.2006. 48 p.Dissertação (Mestrado) Programa de Pós-Graduação em Ciência Animal, Universidade Estadual de Londrina, Londrina, 2006.

BOLIN, C.A. ;CASSELS, J.A.; ZUERNER, R.L.; TRUEBA, G. Effect of vacination with a monovalente Leptospira interrogans serovar hardjo type hardjo-bovis vaccine on type hardjobovis infection of cattle.American Journal of Veterinary Research, v.52, n. 10, p. 1639$1643,1991$.

BOLIN, C.A.; THIERMANN, A.B.; HANDSAKER, A.L.; FOLEY, J.W. Effect of vaccination with a pentavalent leptospiral vaccine on Leptospira interrogans sorovar hardjo type hardjo-bovis infection of pregnate catlle.American Journal of Veterinary Research, v.50, n.1, p.161165,1989

BRASIL. Manual de Leptospirose. Ministério da Saúde. Fundação Nacional de Saúde. Centro Nacional de Epidemiologia. Coordenação de Controle de Zoonoses e Animais Peçonhentos. Programa Nacional de Leptospirose. 2. ed. Brasília: Fundação Nacional de Saúde. 98 p. 1995.

BROD, C. S. et al. Evidência do Cão como Reservatório da Leptospirose Humana: Isolamento de um Sorovar, Caracterização Molecular e Utilização em Inquérito Sorológico. Revista da Sociedade Brasileira de Medicina Tropical, Pelotas, v. 38, n. 4, p. 294-300, jul/ago. 2005.

CASTRO,V.; AZEVEDO,S.S.; BATISTA, C.S.A.; MORAES,Z.M.; SOUZA, G.O.; VASCONCELLOS, S.A.; GENOVEZ, M.E. Soroprevalência da leptospirose em fêmeas bovinas em idade reprodutiva no estado de São Paulo, Brasil. Arquivo Instituto Biológico de São Paulo, São Paulo, v.75, n.1, p.3-11, jan./mar., 2008

DE VRIES,A. Economic Value of Pregnancy in Dairy Cattle. Journal ofdairyScience, Florida, V. 89, n. $10,2006$. 
FAINE, S. Leptospira and leptospirosis. Melbourne: CRC Press, Boca Raton, Florida,p.353, 1994.

FAVERO, M.; PINHEIRO, S. R.; VASCONCELLOS, S.A.; MORAIS, Z. M.; FERREIRA, F.; FERREIRA NETO, J.S. F. Leptospirose bovina, variantes sorológicas predominantes em colheitas efetuadas no período de 1984 a 1997 em rebanhos de 21 estados do Brasil. Arq. Inst. Biol., São Paulo, v.68, n.2, p.29-35, 2011.

FERESU,S.B.; ANN, B.C.; VAN DE,K.H.;KORVER,H. Identification of a serogroup bataviae Leptospira strain isolated from an in zimbabwe. Zentralblatt fur Bakteriologie. n.289, p.929, 1999.

FIGUEIREDO, A. O.; PLLEGRIIN, A.O.; GONÇALVES, V.S.P.; FREITAS, E.B.; MONTEIRO, L.A.R.C; OLIVEIRA,J.M.; OSÓRIO, A.L.A.R. Prevalência e fatores de risco para a leptospirose em bovinos de Mato Grosso do Sul. Pesquisa Veterinária Brasileira, Campo Grande, v.29, n. 5, p.375-381, maio, 2009.

FILHO, J.B.; STRANG, H.B.; BRAZ, M. A. Leptospirose: Tratamento e controle em bovinos. Ciências Agrárias e Saúde. FEA, Andradina, v.5, p. 53-58, 2005 .

GIRIO, R.J.S.; LEMOS,R.A.A. Leptospirose. In: RIET-CORREA,F.; SHILD, A.L.; LEMOS, A.A.;BORGES, J.R.J. Doenças de Ruminantes e Equídeos, Santa Maria: Palloti, v.1, 3. ed. ,cap. 3.p.331-347, 2007.

LANGONI, H.; MEIRELES, L.R.; GOTTSCHALK, S.; CABRAL, K.G.; DA SILVA, A.V. Perfil sorológico da leptospirose bovina em regiões do Estado de São Paulo. Instituto Biológico de São Paulo, São Paulo, 2000.

LEVETT, P. N. Leptospirosis, Clinical Microbiology Reviews. Washington, v.14, n.2, p.269326, 2001.

MARQUES, A, E.; ROCHA, W. V.; DE BRITO, W. M. E. E.; FIORAVANTI, M. C. S.; PARREIRA, I. M.; JAYME, V.S. Prevalência de anticorpos anti-leptospira spp. e aspectos epidemiológicos da infecção em bovinos do Estado de Goiás. Ciência Animal Brasileira, Goiânia, 2010.

MENDES, M.; BITTAR, J.; PEREIRA, W.; ARDUINO, G.; BITTAR, E.; PANETTO, J.; SANTOS, J.. Determinação da prevalência das principais doenças da reprodução no rebanho bovino da região de Uberaba -MG. Ciências Animal Brasileira, Goiânia, 2011.

MINEIRO, A.L.B.B.; BEZERRA, E.E.A.; VASCONCELLOS, S.A.; COSTA,F.A.L.; MACEDO, N.A. Infecção por leptospira em bovinos e sua associação com transtornos reprodutivos e condições climáticas. Arquivo Brasileiro de Medicina Veterinária e Zootecnia, v. 59, n. 5, p. 11031109, 2007.

MOREIRA, RQ.; CABRAL, D.D.; LIMA, A.M.C.; OLIVEIRA, P.R. Soroprevalência de anticorpos Anti-Neospora caninum e anti-Leptospira interrogans em duas propriedades de vacas leiteiras com relatos de prejuízos reprodutivos no município de Goiandira, Goiás. Ciências Animal Brasileira, Goiânia, v.11, n.2,p.396-401, abr./jun.2010.

MORETTIN, P. A.; BUSSAB, W. O. Estatística Básica. 5. ed. São Paulo: Saraiva. 2003.

OLIVEIRA, F. C. Z.; Leptospirose bovina no Estado da Bahia Brasil. Prevalência, sorovares predominantes, distribuição espacial e fatores de risco.2008. 123f. Tese ( Mestrado em Medicina Veterinária) -Faculdade de Medicina Veterinária e Zootecnia, Universidade de São Paulo, São Paulo, 2008.

QUINN, P.J.; MARKEY, B.K.; CARTER, M.E.; DONNELLY, W.J.; LEONARD, F.C. Espiroquetas. In:__ Microbiologia Veterinária e Doenças Infecciosas. Porto Alegre: Artmed, cap. 31, 2005. 179-188p. 
RAMADASS, P.; JARVIS, B. D.; CORNER, R. J.; PENNY, D.; MARSHALL; R. B. Genetic characterization of pathogenic Leptospira species by DNA hybridization. International Journal of Systematic Bacteriology, v.42,p. 215-219, 1992.

RENDE, J. C.; ÁVILA, F. A. Leptospirose bovina: Perfil epidemiológico e dinâmica da infecção como zoonose. Ars Veterinaria, Jaboticabal, v. 19, n.1, p.71-79, 2003.

REBHUM, W.C.. Diseases of dairy cattle. Baltimore: willians \& Wilkins. p. 472-474, 1995.

RIBEIRO, A.C.D.L.et.al. Manual de Bovicultura de Leite -Embrapa -Gado de Leite,Brasília, 2010, cap.11, p. 512-523.

SILVA, N. Doenças Bacterianas Específicas. In: MARQUES, D.C. Criação de Bovinos. 7.ed. ver., atual e ampl.-Belo Horizonte: Consultoria Veterinária e Publicações, 2006. Cap.5.p.494-496.

SOUZA, M.A.; Leptospirose entre diferentes espécies animais em duas propriedades da zona rural do município de UBERLÂNDIA, MG. 2009. 43f. Monografia (Medicina Veterinária) - Faculdade de Medicina Veterinária, Universidade Federal de Uberlândia, Uberlândia, 2009.

TENÓRIO, T.A.G.S.; DE MELO, L.U.H; VASCONCELLOS, S.A.; DE CASTRO, R.S.; DA SILVA, F.F.; LEITE, J.E.B.; RÊGO, E.W.; VAZ, B.B.U.; BORBA, M.A.C.; MELO, M.T.; DE CASTRO, V.B.; CAMPOS, K.M.T.; BERTO, R.S.; MENDES, E.I. Soroprevalência da brucelose e da leptospirose em rebanhos de bovinos leiteiros do Estado de Pernambuco Veterinária Notícias , Uberlândia, v.11, n.2, p.43-48, 2005.

TOMICH, R. G. P.; SERRA, C. V.; BOMFIM, M. R. Q.; CAMPOS, F. S.; LOBATO, Z. I. P.; PELLEGRIN, A. O.; PELLEGRIN, L. A.; BARBOSA-STANCIOLI, E. F. Sorodiagnóstico de doenças da reprodução em rebanhos de bovinos leiteiros de assentamentos rurais de Corumbá, MS. Arquivo Brasileiro de Medicina Veterinária e Zootecnia, Belo Horizonte, v.1, n.1, p. 1678-4162, 2009.

VASCONCELLOS, S.A. O papel dos reservatórios na manutenção de leptospiras na natureza. Comunicação Científica da Faculdade de Medicina Veterinária e Zootecnia da Universidade de São Paulo, V.11, p17-24, 1987.

VIANA, K. F.; ZANINI, M.S.; MOREIRA, E.C. Frequência de anticorpos anti-Leptospira spp em rebanhos bovinos da bacia leiteira do Caparaó, estado do Espírito Santo. Archives of Veterinary Science, v. 15, n. 2, 2010. 


\section{Apêndice e Anexo}

ANEXO A - Questionário Epidemiológico.

Nome da Propridade:

Nome do Proprietário :

No de Animais Coletados:

1- Categoria animal

a- primípara b- multípara

2- Rebanho vacinado

$a-\operatorname{sim} b-$ não

3- Contato com roedores

a- $\operatorname{sim}$ b- não

4 - Há abortos na propriedade

$a-\operatorname{sim} b-$ não

Frequência

5- Ausência de esgoto

$a-\operatorname{sim} b-$ não 